\title{
11 Care on Earth: generating informed concern
}

\author{
Holmes Rolston, III
}

Evolutionary natural history has generated "caring" - by elaborating, diversifying, conserving, and enriching such capacities. A first response might be to take care about that "caring"; the word is too anthropopathic. The framework one expects in contemporary biology is rather termed the evolution of "selfishness" (as if that word were not also anthropopathic). Selfishness, however, is but one form of caring; "caring" is the more inclusive term. Minimally, biologists must concede that organisms survive and live on, and that, over generations, they seek adapted fit. Or, if "seek" is still too anthropopathic, they are selected for their adapted fit. Maybe "select" is still too anthropopathic. Try computer language: the organic systems are "calculating." Whatever the vocabulary, for all living beings some things "make a difference"; they do not survive unless they attend to these things.

At least after sentience arises, neural organisms, human or not, evidently "care." Animals hunt and howl, find shelter, seek out their habitats and mates, feed their young, flee from threats, grow hungry, thirsty, hot, tired, excited, sleepy. They suffer injury and lick their wounds. Sooner or later every biologist must concede that "care" is there. Call these "interests" or "preferences" or whatever; if "caring" is too loaded a term, then call these animal "concerns." Staying alive requires "self-defense." Living things have "needs." One of the hallmarks of life is that it can be "irritated." Organisms have to be "operational." Biology without "conservation" is death. Biology

Information and the Nature of Reality: From Physics to Metaphysics, eds. Paul Davies and Niels Henrik Gregersen. Published by Cambridge University Press (C) P. Davies and N. Gregersen 2010. 
must be "pro-life." If you dislike the connotations of "caring," there are dozens of good biological terms that spiral around this term.

When humans arrive on the scene, "caring" is present by any conceivable standard. So once there was no caring; now "caring" is dominant on Earth. We need an account of its genesis. This will first be descriptive, but the description will demand prescription. Asking what humans and nonhumans do care about invites the question, for any who have choices, of what they ought to care about.

A consensus claim by those in complexity studies is that complex systems must be understood at multiple levels. Another is that simpler systems can generate more complex ones. Even so, neither complexity nor caring can be formalized into any comprehensive algorithmic routines. We will here rise through hierarchies and cross the thresholds requisite to the generation of caring. Complexity capable of caring, at least as we know it on Earth, is middle-range. Protons, electrons, and atoms do not care; nor do galaxies or stars. The human world, in which there is much caring, stands about midway between the infinitesimal and the immense on the natural scale. The greatest complexity we know is at our native range.

By some accounts, humans are dwarfed and shown to be trivial on the cosmic scale. By some accounts, humans are reduced and shown to be nothing but electronic molecules in motion on the atomic scale. But by equally impressive accounts, humans live at the center of complexity. In astronomical nature and micronature, at both ends of the spectrum of size, nature lacks the complexity that it demonstrates at the mesoscales, found in our native ranges on Earth. Perhaps we humans are cosmic dwarfs; perhaps we are molecular giants. But there is no denying our mid-scale complexity. We humans live neither at the range of the infinitely small, nor at that of the infinitely large, but we might well live at the range of the infinitely complex. We live at the range of the most caring; we ourselves might embody the most capacity for caring.

Initially, the evolution of caring on Earth requires the generation of complex chemistries, developing into enzymatic self-reproduction, 
developing into life with self-interest. But caring gets complicated, since selves are implicated. They eat each other, but equally they depend on each other (even on what they eat). They must reproduce themselves. Self-defense requires adapted fit; living things, and hence their cares, are webbed together in ecosystems. There will be "relations" - in today's fashionable term "networking."

Caring is self-contained only up to a point; after that it is caring "about" these relationships, the contacts and processes with which one is networked. It is caring about others: if only a predator caring to catch and eat prey; the prey caring to escape; both caring for their young. Caring will be matrixed and selective within such matrices. Networking will require distinctions, differential concerns.

In humans, there arise more inclusive forms of caring. Such wider vision requires even more complexity, a complex brain that can evaluate others not only in terms of helps and hurts, but also with concern for their health and integrity. This radically elaborates new levels of cultural information, and caring. Humans care about family, tribe, nation, careers, and ideational causes, such as biological science, French literature, or the Christian faith. Ethics shapes caring. In due course, humans alone on the planet can take a transcending overview of the whole - and care for life on Earth.

As good a description of Darwinian natural selection as any, and one that perhaps connects better than others with human culture, is that the story of life on Earth is of the generation and regeneration of caring. We here seek - we "care about" - a grander narrative of this informed concern. There is caring wherever there is "agency," wherever there is "motivation," where there is "locomotion," perhaps even where there are "motors." Science gives us a mechanistic universe, many say, claiming now to have shed anthropocentrism, forgetting that in its original etymology even a "machine" is "for" something. Axiologically, there is the generation of "norms." Cybernetically, there is the generation of "programs." Psychologically, there is the generation of "preferences." Ethically, there arise "duties," "responsibilities." All these concerns are our 
concern here. We need as full a story as we can get about caring on Earth. At length and in the end, we will seek the metaphysical and religious significance of this generation of caring.

\subsection{ATTRACTION: PACTED MATTER}

We have an umbrella word, "attraction," that is applied to everything from gravity to sexual appeal. Perhaps this makes the word too vague to be useful without further specification. But perhaps we can use it to launch our inquiry with the observation that right from the primordial beginnings, long before any processes we might term "caring" have evolved, even elemental matter is prone to pact itself, to gather itself into clumps. From one perspective, in the big bang, everything is flying apart in a universe continually expanding; but from another perspective, in the non-isomorphic universe that results, matter clumps into stars, into galaxies.

In some of these stars, all the heavier elements are forged: more pacting together of electrons, protons, neutrons. Four fundamental forces hold the world together: the strong nuclear force, the weak force, electromagnetism, and gravitation, These range over 40 orders of magnitude; some involve repulsion as well as attraction - the push as well as the pull is used to hold things together. The mix of forces is both remarkable and complex. Apparently, in this universe at least, these forces, and the particle masses and charges involved, have to be about what they are if matter is to become more complex, a prerequisite for anything still more complex developing.

Some of these stars explode again, but matter re-pacts itself, into planets. On (at least) one of these planets, complexity increases again by (so to speak) many more orders of magnitude. On Earth something we do want to call "caring" arises. This is no simple continuum but a complicated, diffracted, and punctuated story. We will be challenged to integrate it.

Beyond aggregation, matter is regularly spontaneously organizing, as when molecules and crystals form. In some situations, especially with a high flow of energy over matter, patterns may 
be produced at larger scales (Prigogine and Stengers, 1984). These patterns may further involve critical thresholds, often called selforganized criticality (Bak, 1996) Such processed are "automatic" sometimes called "self-organizing." Initially the "auto" should not be taken to posit a "self" but rather an innate principle of the spontaneous origination of order. Such features of matter are prerequisite to the later formation of proactive "selves. "

\subsection{CYBERNETIC NATURE! GENES "FOR"}

In wild nature, in view of entropy, only minimal levels of complexity can arise automatically. More complex biomolecules will not be reproduced often and reliably enough by spontaneous assembly. Advanced levels will require maintenance of the formed and functional structures and processes. Breakthroughs to new levels of complexity may be initially spontaneous, but their maintenance will require directed assembly and repair because otherwise the spontaneous breakdown rate will overwhelm the spontaneous construction rate. Spontaneous formation is a starter, but if you have to start from scratch each time, you do not get far. Natural history evolves first simply by "templating," but later on this becomes "instruction"; "forming" becomes "informing."

A major transition, launching endless possibilities in both complexity and in caring, happens with the origin of life, which, at least as we now inherit it, is always coupled with genetics. Genetic cybernetics is often said to be about "information," but it is not just information "about" it is information "for." A genetic sequence has a potential for being an ancestor in an indefinitely long line of descendant genotype/phenotype reincarnations. The gene does not contain simply descriptive information "about" but prescriptive "for." The gene will be a gene "for" a trait because there has been natural selection "for" what it does contributing to adaptive fit. The preposition "for" saturates both natural selection and genetics. Traits get "selected for"; and the code "for" these gets simultaneously "selected for" in the genes and "mapped"; there is the genotype that 
records the know-how to make the functional structure and processes in the phenotype. In this sense, there is specified complexity.

Biologists may insist that in natural selection the mutation and shuffling process is blind, random. Some recent geneticists think it more probabilistic (Herring et al., 2006). In the results that this nonintentional process produces, however, genes do act directed toward a future, under construction. Unlike natural selection "for," wherever it shows up in genetics, there is a "telos" lurking in that "for." Biological functions are "teleonomic" (Mayr, 1988), contrasted with causation (including the "pacting" causation and automatic spontaneous organization) in physics and chemistry. Magmas crystallizing into rocks, and rivers flowing downhill have results, but no such "end."

Can genes care? Can genes generate care? Initially an answer is: genotypes cannot care, but some of the phenotypes they generate can. Genes cannot "intend" anything, any more than can the forces of natural selection operating on genes. Interestingly, however, some theoretical biologists and philosophers have begun using the term "intentional" as descriptive of biological information in genes. John Maynard Smith insists: "In biology, the use of informational terms implies intentionality" (Maynard Smith, 2000, p. 177). That word still has too much of a "deliberative" component for most users, but what is intended by "intentional" is this directed process, going back to the Latin intendo, with the sense of "stretch toward," or "aim at." Genes have both descriptive and prescriptive "aboutness" they do stretch toward what they are about. Genetic information is "intentional" or "semantic" in this perspective, if it is for the purpose of ("about") producing a functional unit that does not yet exist. It is teleosemantic.

Where there is information being transmitted, there arises the possibility of mistakes, of error. The DNA, which is coded to make a certain amino acid sequence that will later fold into a protein segment, can be misread. If the reading frame gets shifted off the "correct" triplet sequence, then the "wrong" amino acids get 
specified, and the assemblage fails. There is "mismatch." Often there is machinery for "error-correction." This complexity must "discriminate." None of these ideas makes any sense in chemistry or physics, geology or meteorology. Atoms, crystals, rocks, and weather fronts do not "intend" anything and therefore cannot "err." A mere "cause" is pushy but not forward-facing. By contrast, a genetic code is a "code for" something, set for control of the upcoming molecules that it will participate in forming. There is proactive "intention" about the future.

Such "caring" requires considerable complexity in genetics. There is transcription, translation, signaling, messaging copying, reading, coding, regulation, communication. Genes produce structural proteins, but many genes are regulatory. The whole idea of regulation is a precursor toward "caring," which makes no sense in the inanimate world. The interaction between structure and regulation has proved complex. Contemporary bioinformatics is limited by lack of computing power adequate for analysis of the complexity of the genetic sequences under study. The genetics must be complex because the proteins produced must be complex. One challenge is to produce widely variant proteins by ringing the changes on genetic sequences. Another is to produce highly stereospecific biomolecules that function to discriminate - "recognize" is the usual biologist's term - the needed required (or dangerous) resources: as when a hemoglobin, on account of its allosteric conformation, uses an iron molecule to bind oxygen and transport it from lung to cell.

\subsection{GOING CONCERNS: ORGANISMIC}

SELF-ORGANIZATION AND SELF-DEFENSE

If you doubt that there is "caring" in the genotype, then move to the level of the phenotype. "Skin" is a sign of caring. Perhaps you wish to say with "bark" only that life has to be "protected." Biologists will take that term "protect" inside the skin to immune systems, and, for that matter, down to lipid bilayers. If you prefer scientifically more imposing words than "skin" or "bark", then use that of 
Humberto R. Maturana and Francisco J. Varela: "autopoiesis" (autos, "self" and poiein, "to produce") (Maturana and Varela, 1980). At this level in natural history, there has emerged a somatic self with know-how to protect it. If this isn't yet "caring," it is on the threshold of it; we are approaching another complex criticality.

Living things are self-maintaining systems. They grow; they are irritable in response to stimuli. They reproduce. They resist dying. They post a discrete (if also semipermeable) boundary between themselves and the rest of nature, and they assimilate environmental materials to their own needs. They gain and maintain internal order against the disordering tendencies of external nature. They keep recomposing themselves, whereas inanimate things run down, erode, and decompose. Life is a local countercurrent to entropy. Organisms pump out disorder. This self has to be maintained against entropy, or, if you like, against "aging." The constellation of these characteristics is nowhere found outside living things, although some of them can be mimicked or analogically extended to products designed by living systems. A crucial line is crossed when abiotic formations get transformed into loci of information. The factors come to include actors that exploit their environment.

Stuart Kauffman concludes a long study of the origins of order in evolutionary history:

Since Darwin, biologists have seen natural selection as virtually the sole source of that order. But Darwin could not have suspected the existence of self-organization, a recently discovered, innate property of some complex systems ...

Selection has molded, but was not compelled to invent, the native coherence of ontogeny, or biological development ... We may have begun to understand evolution as the marriage of selection and selforganization.

(Kauffman, 1991)

Evolution is a complex combinatorial optimization process.

(Kauffman, 1993, p. 644) 
In this generation of life, "pacting" reappears in biological forms -first simply, with aggregating cells, that is, cells sticking together, not unlike aggregating matter in physics and chemistry; later there emerges integrated multicellular life. There is "organization," now concerted "self-organization," the building of "organs." Although integrated and differentiated multicellularity (as contrasted with microbial aggregation) did not arise for a long time (over a billion years!), when it did arise, it arose more than once (Bonner, 1998).

Complexity, as is often noticed, is modular. Within organismic skin or bark, there are modules that need boundaries, compartments, and walls, or at least boundary zones. In living systems, a principal form of this modularity is cellular. There must be some means of preserving modular identity. Distinction will require differentiation. That makes things more complex and invites open-ended differentiation, escalating the complexity. One measure of complexity is the number of different cell types. Another measure is the number of different kinds of interaction. These modules in their nested sets must be reproduced by directed reproduction. This level of information, as we were saying, is proactive about assembly of these metabolic modules and organs. Again, if this is not sufficient for caring, it is a necessary precursor.

There is not much point to modular complexity unless it enables more sophisticated information processing. An organism can survive better if it can exploit the beneficial regularities and deal with more of the contingencies in its environment than a competing organism. Organisms are "built to run, not fail." They are "overengineered" with layers of control, selected for more complexity, more failsafe protections, in the defense of their caring (Oliveri and Davidson, 2007). Perhaps this will be through tried and true stereotyped behaviors that win out statistically. But at least some organisms might better survive if there is flexibility; and this requires that an organism evaluate internal and external signals and respond by increasing or decreasing metabolisms and behaviors. The organism has to deal with nested sets of hierarchically organized proteins, 
lipids, enzymes, organelles, organs, an organismic system; a whole with its parts, surviving and reproducing in an ecosystem.

In modular systems, there will be systems and subsystems. Rarely will each module be equally and identically connected to each and all the other modules. Such hierarchical stratified systems must be described on multiple descriptive and interpretive levels. The construction of complexity begins with the simple and becomes more and more complex; the story is from the bottom up. But after certain thresholds are reached, parts can be differentiated. There is division of labor, a principal result of multicellularity. Often these relations are nonlinear; causes and effects are not proportionally related. There may be domains in which small changes in causal inputs make major changes in outputs, or vice versa: where huge changes in causal inputs make little change in outputs. If the modularity is evolving, the organic system will build by reiteration and modification of modules (mutations into something a little different), although there may also be novel sorts of modules, perhaps by co-option.

This requires more careful control of, and experimenting with, what is somatically inside the organism, but this is in response to external opportunity and threat. Modules interact not only with themselves, but also in and with an environment. Outside, the organism must also deal with thresholds and phase transitions, as when ice melts and there is water to drink. An epidemic microorganism might cause epidemic disease in a forest, and animals and birds must migrate to elsewhere on the landscape. Environments can be of multiple kinds, affecting the modular complexity. The environment of a complex biological organism is a mixedly ordered and chaotic mosaic with its variously predictable, probable, and indeterminate elements.

Like the ecologists who come later and study ecosystems to find that they resist law-like specification, organisms have evolved in environments that are both patterned and open. Much is local and site-specific. The courting display of the boreal owls differs from 
that of the ivory-billed woodpeckers, and each makes a certain sense in their niches in their environments. So? Rejoice in the particular and local forms of caring.

Such an Earth might first be thought to be a disvalue, but, on further investigation, if organisms operate in environments that are neither totally predictable on the one end of a spectrum, nor totally chaotic on the other, this generates a natural history that is much more "interesting" just because of its combining nomothetic and idiographic elements (to use the technical terms). If the world is perplexing, this stimulates more complex ways of dealing with it, and this perplexing-driving-complexing in turn demands more diverse caring. If some increment of capacity for innovative behavior appears, this potential will become more fully actualized in a challenging environment, with survival success. This will be repeated continually. Not only does living on such an Earth require organisms to generate more complexity in the parts, it also requires complex constructions to emerge that can oversee the behaviors of the parts; the top overtakes the bottom. So the ATP is being hydrolyzed to ADP, and the hemoglobin moves at an increased pace because the coyote is chasing the ground squirrel. And this is not just the nitrogen atoms in muscles and the iron atoms in hemoglobin, supporting the chase. The genes are being unzipped and read because the coyote needs more ADP. Genes are sometimes executive, as with the assembly of embryo. But when the organism has been constructed and is launched into ongoing metabolism, the phenotypic organism becomes equally executive. The organism uses its genes as a sort of Lego kit, in which it finds the assembler codes for the materials it conies to need.

Genetic behavior in and of itself is stereotyped, although these routines may be labile enough to respond to environmental stimuli. Stentor roeseli, a trumpet-shaped one-celled aquatic organism, has a mouth at the top and attaches itself by a foot to the substrate. If irritated, it contracts, or ducks, bending first this way and then that, or reverses the ciliary movement of its peristome to sweep water 
currents away. It may withdraw into a mucous tube about the base, to return after a few minutes, and, upon further irritation, repeat various avoidance reactions. But finally, with a jerk, it will break the attachment of its foot and swim away to attach itself elsewhere. If the irritation continues, it dislodges and tumbles away until by chance a non-noxious solution is found, whereupon it stops moving; the random locomotor variation ceases.

Stentor has no career memory; the particular Stentor cannot store previous solutions and invoke them at the next irritation. It cannot, for instance, invoke memory to "know" the next time to continue in the same direction as before as a direction of likely escape from irritation. There is no conditioned learning. Nevertheless, there is a sense in which this is intelligent and caring behavior, if also at a low level - from our human perspective. If irritated, Stentor generates and tests for more congenial places to live. There is probing and feedback. Stentor is doing this because it worked in previous Stentors, who survived, and this "intelligent" behavior got coded in the DNA. More complex organisms can climb a gradient or preferentially select food.

A still more sophisticated level of complexity, moving further toward caring, is reached with the capacity for learning, for acquired behavior. A coyote has a memory and conditioned learning; it can remember in which directions to run for cover. This requires developing neural or other capacities to operate in the subtleties of context, which in turn generates new levels of caring.

Such complexity involves emergence. The mutual interactions of the components and subsystems result in a capacity for behavior of the whole that transcends and is different from that in the parts and unknown in the previous levels of organization. Nursing evolves incrementally; and yet later on, there are mothers who nurse their young, while earlier there were none. They are genetically impelled to do so, but they also learn from watching other mothers nursing their young. They learn when and how to wean their young. Human mothers discipline and teach their young about what to eat and what not to eat. Now there is acquired learning. 
Genes have to be understood from both a contemporary and a historical perspective. Why is the plant bending toward the sun? ("Orienting" itself, which we might think of as a precursor of caring.) Biologists need both proximate explanations and evolutionary explanations (Mayr, 1988, p. 28). Cells on the darker side of a stem elongate faster than cells on the brighter, side: because of an asymmetric distribution of auxin moving down from the shoot tip. But the explanation at a more comprehensive level is that, over evolutionary time, in the competition for sunlight, there were suitable mutations, and such phototropism increases photosynthesis.

So the explanation of this orienting stretches from the microbiology over a few hours to that of macroscale natural history over millennia. At more complex levels, there will be proximate explanations of how the mind shapes behavior, moving mammal mothers to nurse their children. At a more comprehensive explanatory level $>$ this is because such mothers increased their number of offspring and were naturally selected. If you like, and to phrase it a little provocatively, there is natural selection for better caring. In cultures, this continues with cultural mores enabling one generation to produce and rear the next. The macrohistory drives the microhistory. The pro-life explanations can get prolific.

At this level, top-down and bottom-up issues arise. Where there is brain, this is as evidently top-down as the head is at the top of the body, directing its motions (as we later elaborate). These brained organisms do not behave the way they do simply on account of anything we know about electrons and protons, but on account of what we know about neural networks: indeed, on account of what we know about predators and prey, or, in human affairs, about trust funds and stock-markets, or how to will an estate to the next generation.

Yes, when life appears, there is pro-life caring; but - hard-nosed biologists may now insist - the caring is entirely selfish. George C. Williams puts it bluntly: "Natural selection ... can honestly be described as a process for maximizing short-sighted selfishness" 
(Williams, 1988, p. 385). Richard Dawkins has long insisted that every gene is a "selfish gene" (Dawkins, 1989). Here a principal worry, especially for any who have been apprehensive about my use of "caring" is that a moral word, "selfish" has been taken out of the human realm and applied to all living things, whether oysters or DNA molecules. At least, at the genetic level, biologists must concede that seldom, if ever, can single genes manage to be selfish, as genes must cooperate with each other in the whole organism, which survives or dies depending on this complex integration.

Since we are en route to an understanding of how "caring" has been generated, why not use a less pejorative word and say that each organism is in pursuit of - that is - values, its own proper life (from the Latin proprius: "one's own"), which is all that the (nonhuman) individual organism either can or ought to care to pursue? Bacteria, insects, crustaceans - including also the sentient creatures, the mice and chimpanzees - are projects of their own, each a life form to be defended for what it is intrinsically. An intrinsic value, from the perspective of biology, is found where there is a constructed, negentropic, cybernetic identity that is defended in such a somatic organismic self with an integrity of its own. Using its genes, the organism is acting "for its own sake," or, more philosophically put, "to protect its intrinsic value." These are "axiological genes."

Further, the increasing complexity is feeding the caring. Complexity, especially that which mixes order and openness, generates attention, preferential orientation. Such complexity produces perplexity. There arises both opportunity and threat. The organism can have fortunes and misfortunes. There can be cooperation and competition. The organism will have to generate and test better solutions to its problems. This escalates complexity, especially where there are competing cares that are matters of life and death. Biologists refer to this as coevolution, and notice that the dynamic ("the coevolutionary arms race," they may say) drives the generation of complexity. In this sense, a world with less chance could be a world with less caring. 


\subsection{SPECIES CONCERNS: (RE)PRODUCTION} OF KINDRED OTHERS

Next, the horizon of caring enlarges, just because of the genetics. Even if biologists retain the "selfish" metaphor, the selfish caring gets "pacted" together, skin-out, as intensively as we saw it before skin-in. Not only must genes cooperate with each other in the whole organism, but the whole organism, the phenotype, gets placed in a species line. That first happens in reproduction: all species must "care" about reproduction - at least by Darwinian accounts that is their priority care - otherwise they become extinct.

So behaviors are selected that attend proportionately to the whole family: what biologists call "kin selection." One can still insist that the individual acts "selfishly" in his or her own interests, but "selfish" is now being stretched to cover benefits gained by "caring about" father, mother, niece, nephew, cousin, children, aunts, uncles, and so on, however far one chooses to look along the indefinitely extended lines of relationship, lines that fan out eventually to all conspecifics (half of which are also potential mates, which sometimes also need to be cared about). So it turns out that any such individual's "own proper life" is not exclusively individually owned, but is scattered about in the family, and that the individual competently defends its so-called "self" whenever possible and to the extent that this is manifested in the whole gene pool. This means that values about which the organism cares can be held intrinsically only as they are more inclusively distributed, and that places us in a position further to consider this process by which caring complexity is generated.

This proactive agency "cares" (still using that word provocatively) about the ongoing species line. Generation requires regeneration. In reproduction, organisms reproduce themselves by passing a single set of minute coding sequences from one generation to the next, with the next generation self-organizing from this single transferred information set. A single totipotent cell, using provided maternal resources, transforms itself into a whole complex organism. What is 
conserved is not the matter, not the organism, not the somatic self, not even the genes, but a message that can only be conserved if - and only if - it is distributed, disseminated.

The passage of genes is the passage of species. The genes are the species writ small, the macroscopic species in microscopic code; the species is the genes writ large, the microscopic code in macro- scopic species. The survival of the genes is the survival of the kind and vice versa, since genes code kind, and kind expresses genes. A genetic set codes the kind, representatively; and the organism, an expression of the kind, presents and represents the kind in the world.

Reproduction is typically assumed to be a need of individuals, but since any particular individual can flourish somatically without reproducing at all, indeed may be put through duress and risk or spend much energy reproducing, by another logic we can interpret reproduction as the species keeping up its own kind by reenacting itself again and again, individual after individual. It stays in place by its replacements. In this sense, a female grizzly bear does not bear cubs to be healthy herself, any more than a woman needs children to be healthy. Rather, her cubs are Ursus arctos horribilis, threatened by nonbeing, recreating itself by continuous performance. A species in reproduction defends its own kind. A female animal does not have mammary glands nor male animal testicles because the function of these is to preserve its own life; these organs are defending the line of life bigger than the somatic individual. The lineage in which an individual exists dynamically is something dynamically passing through it, as much as something it has. The locus of the intrinsic value - the value that is really defended over generations - seems as much in the form of life, the species, as in the individuals, since the individuals are genetically impelled to sacrifice themselves in the interests of reproducing their kind. What they "care about" is something dynamic to the specific form of life; they are selected to attend to the appropriate survival unit.

Selfish genes these reproducing individuals may have, but the genes "care more about" the species (so to speak) than the individual 
and its concerns. The solitary organism, living in the present, is born to lose; all that can be transmitted from past to future is its kind Although selection operates on individuals, since it is always an individual that copes, selection is for the kind of coping that succeeds in copying, that is reproducing the kind, distributing the information coded in the gene more widely. Survival is through making others, who share the same valuable information. The organism contributes to the next generation all that it has to contribute, its own proper form of life, what it has achieved that is of value about how to live well its form of life. Survival is of the better sender of whatever is of genetic value in self into others. Survival of the fittest turns out to be survival of the senders. What genes are "for," we earlier said, is to be ancestors in an indefinitely long line of descendant genotype/ phenotype reincarnations. Genes get "spread" around, or "distributed" by organisms who do not simply live for their "selves," but to spread what they know to other selves. Again, if doubters wonder whether this is yet to be called "caring," no doubt it is moving in that direction.

\subsection{NATURAL SELECTION: SEARCHING FOR ADAPTED FIT}

On Jupiter and Mars, there is no natural selection. Nothing is competing, nothing is surviving, nothing has adapted fit. Nothing cares about any thing. Even on Earth, climatological and geomorphological agitations continue in the Pleistocene period more or less like they did in the Precambrian. But the life story is different, because in biology, unlike physics, chemistry, geomorphology, or astronomy, something can be learned, first genetically and later neurally. The result, where once there were no species on Earth, there are today five to ten million. These species have been required to fit together in ecosystems, with adapted fit.

Complexity is modular, internally modular, as we earlier noticed from the skin in, but with adapted fit, complexity becomes also externally modular, from the skin out. Complexity is an 
organism-in-environment dialectic. Ecosystems have what the ecologists call niche space; rich ecosystems have myriads of such niches. A niche is both a place and a role in that place. Organisms make a living in a niche; they get webworked and fitted into trophic pyramids, into feedloops and feedback loops. They get figured into hypercycles, which are more complicated such loops. Upper levels depend on lower levels in these biotic communities, which means that the simpler forms of life, such as microbes and plants, do not vanish but remain essential in the pyramid of life.

This webworking remains essential, first, in the energycapturing processes (animals would die without plants) but is also required in the material recycling processes (such as decay). Every living organism depends on value capture, often equally on feeding, whether grazing or predation, and on symbiosis. The biotic sector runs by need-driven individuals interacting with other such individuals and with the abiotic and exbiotic materials and forces (such as water and humus). Genotypes generate novel variations in phenotypes. The environment is not capricious, but neither is it regular enough to relax in. One always needs better detectors and strategies.

Dialectic with the loose environment (rich in opportunity, noisy, demanding in know-how) invites and requires creativity. The individual and the environment seem like opposites; they are really apposites; the individual is set opposed to its world but is also appropriate to it, in a niche, with adapted fit, faced with fortunes and misfortunes. The system has both order and openness, which invites more sophisticated caring. Situated environmental fitness often yields a complicated life together. Ecosystems are more or less stable, stable enough for natural selection to work dependably in them, and yet, equally often, the interactions are too messy to find the law-like regularities that scientists seek (Solé and Bascompte, 2006). Here ecologists may find such systems too complex to model effectively.

When such complexity builds up, life becomes something of an adventure. Living forms evolve in response to increasing niches 
in varied topographies, seen for instance in rapid and diverse insect speciation, resulting in highly specialized forms. Organisms must seek their niches. The mobile ones seek their habitats, seeking survival in these niches in which they are adapted: But again, this is not simply internal self-preservation, not merely successful habitation of a niche. Selection places the individual on an ongoing species line; in a search for better adapted fit.

Natural selection, hard-nosed biologists may insist, does not "care." David Hume claimed that nature "has no more regard to good above ill than to heat above cold, or to drought above moisture, or to light above heavy" (Hume, 1972, p. 79). Or to life above nonlife, he would have added. That indifference can seem true from some perspectives, especially in the short term, although day-to-day nature is an impressive life support system. Sometimes it even seems true in the long term; every organism dies, species go extinct. But (as is always the case in complex systems) there is another perspective.

Nature on Earth has spun quite a story, making this planet with its landscapes, seascapes, and going from zero to five billion species in five billion years, evolving microbes into persons. Perhaps to say that nature "has regard" for life is the wrong way of phrasing it; we do not want to ascribe conscious caring to nature. Still, nature is a fountain of life. Nature is genesis. As a means to this genesis, natural selection demands fitness. Selection for adapted fit is a strange kind of indifference. Further, this fitness is not measured by an individual's own survival, long life, or welfare. Fitness is measured by what any individual can "contribute to" the next generation in its environment. Such fitness is not individualistic, not "selfish" at all; it is fitness in the flow of life, fitness to pass life on, to give something to others who come after.

Fitness is the ability to contribute more to the welfare of latercoming others of one's kind living in such niches, more relative to one's "competitors." That is an interesting way to think of natural selection: natural selection facilitates congruence between generations, selecting what genes, structures, and processes keep 


\section{HOLMES ROLSTON, III}

regenerating life in the midst of its perpetual perishing. In view of the larger religious horizons in which we are eventually interested, one could even employ a religious metaphor: fitness is "dying to self for newness of life" in a generation to come. Or, if you are not ready for that metaphor, still clinging to the metaphor of "indifference," then perhaps you have started to puzzle about when, during this long elaboration of life, "caring" ceases to be metaphorical and becomes literal.

\subsection{NEURAL CONCERNS: HEADING UP FELT EXPERINCE}

Your caring about caring is being done in the most complex object in the known universe: the human brain - and you just illustrated some of this complexity when you paused to puzzle over my preceding doubling-up of words: "caring about caring." Your primate brain, integrated with hands and legs, was generated as a survival tool in a "jungle" (or, more formally: a complex and chaotic world). Using instinct and conditioned behavior, lemurs "figure out" probabilities; there is that much order and contingency enough to churn the evolution of skills. This brain, in terms of our present interests, proved to be not only an impressive survival instrument; it did so by radically elaborating capacities for caring.

One of the most startling of such elaborations is the capacity for felt experience. The brain-object sponsors a subject with inwardness. Next after that, this subject/object brain elaborates its capacities for cognitive evaluation of the world that the embodied brain is moving through with such felt experiences. Now no one will deny that we have reached "caring" proper. At some critical level, complexity can become aware and, at a still higher threshold, self-aware. There emerges somatic self-awareness.

Animal brains are already impressive. In a cubic millimeter (about a pinhead) of mouse cortex there are 450 meters of dendrites and one to two kilometers of axons. The mouse brain is selectively organized; the mouse is interested in seed and ignores similar- 
looking pebbles. Interestingly, in terms of our interest here, although empathy is often thought to be unique to higher primates, possibly limited to humans alone, there is suggestive evidence even in mice that heightened sensitivity to pain occurs with the observation of familiar mice in pain. They seem to have brain enough for at least precursor capacities to sense what their fellow rodents are experiencing (Langford et al., 2006).

The human brain has a cortex 3000 times larger than that of the mouse. Our protein molecules are 97\% identical to those in chimpanzees, differing by only $3 \%$. But we have three times their cranial cortex, a 300\% difference in the head. This cognitive development has come to a striking expression point in the hominid lines leading to Homo sapiens, going from about 300 to 1400 cubic centimeters of cranial capacity. The connecting fibers in a human brain, extended, would wrap around the Earth 40 times.

The human brain is of such complexity that descriptive numbers are astronomical and difficult to fathom. A typical estimate is $10^{12}$ neurons, each with several thousand synapses (possibly tens of thousands). Each neuron can "talk" to many others. The postsynaptic membrane contains over a thousand different proteins in the signal-receiving surface; "The most molecularly complex structure known [in the human body] is the postsynaptic side of the synapse," according to Seth Grant, a neuroscientist (quoted in Pennisi, 2006). Ever more intricate molecular interactions within synapses have made possible the circuitry that underlies our ability to think and to feel. These are "smart proteins." Over a hundred of these proteins were co-opted from previous, non-neural uses; but by far most of them evolved during brain evolution. "The postsynaptic complexes and the [signaling] systems have increased in complexity throughout evolution," says Berit Kerner, geneticist at the University of California, Los Angeles (quoted in Pennisi, 2006).

What is really exciting is that human intelligence is now "spirited," an ego with felt, self-reflective psychological inwardness. In the most organized structure in the universe, so far as is known, molecules, 
trillions of them, spin round in this astronomically complex webwork and generate the unified, centrally focused experience of mind. For this process neuroscience can as yet scarcely imagine a theory. A multiple net of billions of neurons objectively supports one unified mental subject, a singular center of concern and experience. Synapses, neuro-transmitters, axon growth - all these can and must be viewed as objects from the "outside" when neuroscience studies them.

But what we also know, immediately, is that these events have "insides" to them: subjective experience. There emerges cognitive, existential, phenomenological self-awareness. There is "somebody there" already in the higher animals, but this becomes especially "spirited" in human persons (Russell et al., 1999). Very good evidence for this high-level spiritedness is found in how, when we persons make discoveries in neuroscience and genetics, this generates metaphysical and religious concerns. Our nearest relatives on Earth, such as the chimpanzees, do not come within a hundred orders of magnitude of such capacities, either for scientific cognition or for "spirited" (much less "spiritual") caring what to make of living on an Earth with such remarkable generative powers.

\subsection{MINDING CONCERN: IDEA(L) COMMITMENTS}

All this "heads up" - with increased "top-down" causation - in selfreflective critical agents who have the capacity to build cumulative transmissible cultures. An information explosion gets pinpointed in humans. Humans alone have "a theory of mind"; they know that there are ideas in other minds, required for making these linguistic cultures possible. Such sophistication of language, grammar, and cognitive evaluation of felt and sought experiences brings increasingly complex caring. "Hundreds of millions of years of evolution have produced hundreds of thousands of species with brains, and tens of thousands with complex behavioral, perceptual, and learning abilities. Only one of these has ever wondered about its place in the world, because only one evolved the ability to do so" (Deacon, 1997, p. 21). 
This cognitive network, formed and re-formed, makes possible virtually endless mental activity. The result of such combinatorial explosion is that the human brain is capable of forming more possible thoughts than there are atoms in the universe. We humans are the most sophisticated of known natural products. In our hundred and fifty pounds of protoplasm, in our three-pound brain is more operational organization than in the whole of the Andromeda galaxy. Some transgenetic, nonlinear threshold seems to have been crossed. The geneticists reporting the sequencing of the human genome called this crossing a "massive singularity that by even the simplest of criteria made humans more complex" (Venter et al., 2001, p. 1347). All this activity is expressed in ever-elaborating forms of caring.

There is only one line that leads to persons, but in that line at least the steady growth of cranial capacity makes it difficult to think that intelligence is not being selected "No organ in the history of life has grown faster" (Wilson, 1978, p. 87). One can first think that in humans enlarging brains are to be expected, since intelligence conveys obvious survival advantage. But then again, that is not so obvious, since all the other five million or so presently existing species survive well enough without advanced intelligence, as did all the other billions of species that have come and gone over the millennia. In only one of these myriads of species does a transmissible culture develop; and in this one it develops explosively, with radical innovations in cognition and caring that eventually have little to do with survival. Grigori Perelman sought and found a proof to the Poincaré conjecture in mathematics, transforming irregular spaces into uniform ones (Mackenzie, 2006). Edward O. Wilson cares for the conservation of his ants, where "splendor awaits in minute proportions" (1984, p. 139).

The power of ideas in human life is as baffling as ever. The nature and origins of language are proving to be, according to some experts in the field, "the hardest problem in science" (Christiansen and Kirby, 2003). Neuroscience went molecular (acetylcholine in synaptic 
junctions, voltage-gated potassium channels triggering synapsizing) to discover that what is really of interest is how these synaptic connections are configured by the information stored there, enabling function in the inhabited world. Our ideas and our practices configure and reconfigure our own sponsoring brain structures.

Thoughts in the conscious mind form and re-form, or, most accurately, in-form events in this brain space. We neuroimage blood brain flow to find that such thoughts can reshape the brains in which they arise. Our ideas and our practices configure and reconfigure our own sponsoring brain structures. In the vocabulary of neuroscience, we map brains to discover we have "mutable maps" (Merzenich, 2001, p. 418). For example, with the decision to play a violin well, and resolute practice, string musicians alter the structural configuration of their brains to facilitate fingering the strings with one arm and drawing the bow with the other (Elbert et al., 1995).

With the decision to become a taxi driver in London, and several years of experience driving about the city, drivers likewise alter their brain structures, devoting more space to navigation-related skills than have non-taxi drivers (Maguire et al., 2000). Similarly, researchers have found that "the structure of the human brain is altered by the experience of acquiring a second language" (Mechelli et al., 2004). Or by learning to juggle (Draganski et al., 2004). Or, we may as well suppose, by years of wondering how to solve the Poincaré conjecture, or how to classify and conserve the ants. The human brain is as open as it is wired up. No doubt our brains shape our minds, but also our minds shape our brains. The process is as top down as it is bottom up. Compare weather, a very complex system, with those resolute violin players remapping their brains.

Humans develop a discursive language in which words and texts become powerful symbols of the world, of the logic of that world, and of our place in the world. Humans have a double-level orienting system: one in the genes, shared with animals in considerable part; another in the mental world of ideas, as this flowers forth from mind, for which there is really no illuminating biological analog. 
We can now care about what is not at present seen (heard, tasted). There can be, so to speak, concern at a distance, caring not only interestedly but also disinterestedly about others. When knowledge becomes "ideational," these "ideas" make it possible to conceptualize and care about what is not present to felt experience. Chimps cannot care about the Ugandans in poverty, even if they encounter the poor at the edge of their forest, but Christians elsewhere in the world may, although they have never been to Uganda.

Conditioned learning among coyotes must take place in actual environmental encounter; but humans can imagine encounters, project them hypothetically, and learn from their imaginings. They have an idea-space, in their minds, which they can use as a trial-anderror simulator, and test in thought-experience behaviors that might gain what they care about. Such an idea-evaluator is faster and safer than trials conducted in the real world. The mental simulator can project the outcomes of such trials, and choose the best ones to test. Even the higher animals can do some of this, but human rationality enables humans to anticipate quite novel futures, to choose potential options, to plan for decades according to chosen simulations, or policies, and to rebuild their environments accordingly. The result is the capacity to care for idealized futures, and to work for such futures. Global capitalism is working now to make the rich richer and the poor poorer, but what if ... ?

\subsection{COMMUNITARIAN CONCERN: TRIBALISM AND BEYOND}

The result of these ideational powers - although persons continue to act in their generic self-interest - is to pull the focus of concern off self-center and bring into focus others in the community of persons. The rapid evolution of the human brain is driven not so much by the need for skills in tool-making or confronting the natural world as by the need to deal with social complexity, especially bonding cooperatively with others (Dunbar and Shultz, 2007). This drives the evolution of complex language, requiring complex and synaptically 
flexible brains. Bodily encounter presents us to each other; language with theory of mind "represents" (re-presents) each to the other. The single self must find a situated social fitness; a person ethically adapts to his or her neighbors. This produces community: initially tribalism. Tribalism - or, a little more inclusively, patriotism - is welcome, up to a point, but does caring evolve any further?

From the biological point of view, if natural selection operates on humans, it first seems plausible that those who care for self and family will out-reproduce those who care for any broader community. But individuals in their families are located within local communities, which, classically, have been tribes, bound together by their cultural mores. These mores can be beneficial when tribe encounters tribe. Group selection, long out of favor in biology, has been recently resurrected (Sober and Wilson, 1998). Tribes of "altruistic" cooperators will out-reproduce tribes of selfish cooperators. Tribal ethics urges cooperating with kin and neighbors and defending the tribe against outsiders, often with the backing of tribal gods, or in sacred trust to ancestors. The benefits gained in out-group competition outweigh the costs of in-group cooperation. So we generate patriots in battle serving for God and country and the Rotarians building their public spirit.

But equally, Sober and Wilson insist, there is no "universal benevolence." "Group selection does provide a setting in which helping behavior directed at members of one's own group can evolve; however, it equally provides a context in which hurting individuals in other groups can be selectively advantageous. Group selection favors withingroup niceness and between-group nastiness. Group selection does not abandon the idea of competition that forms the core of the theory of natural selection" (Sober and Wilson, 1998, p. 9).

Even from evolutionary theory, however, one can reach limited reciprocity with the competing out-groups. These others are not always enemies; they may be tribes with which we wish to trade. Or form alliances. A principal fact of modern life is increasingly wide, even global networks of reciprocity, evidenced in defense treaties and 
world trade, both cooperative and competitive. Here another threshold begins to be crossed, from tribalism to a more inclusive sense of community, and here Darwinian natural selection ceases to have sufficient explanatory power.

Beginning with a sense of one's own values to be defended, caring can sometimes become more "inclusive," recognizing that one's own self-values are widely paralleled, a kind of value that is distributed in myriads of other selves, in my tribe and in others. One comes to participate or share in this larger community of valued and valuing agents. The self-defense of value gets multiplied and divided by this interactive network of connections. The defense of one's own values gets mixed, willy-nilly, with the defense of the values of others.

Such acts can be understood in terms of conserving what the actors value, but the conservation of biologically based value underdetermines such events. The self is not simply biological and somatic, but cultural and ideological. What the self values can be sustained only if people act in concert. Cultural reproduction, conserving what one values in one's heritage, is as much required as is conserving one's genes. But much of one's cultural heritage is transtribal; one is drawn to the church catholic, to democracy, to a sense of fairness in international business, to conserving tropical forests.

All we had before was a concern for one's own advantage, but here "own advantage" has expanded over first to "shared advantage," "mutual advantage," not for all benefits but for many, which are shared first in the genetic kin and secondly in those who are axiologically kin, that is, who share one's culturally acquired values. These benefits often diffuse into those that cannot be differentially enjoyed - such as public safety or the right to vote, since what makes society safe and democratic for me (life preservers at the pool, free elections) confers these benefits at once on others. Trade works only if all keep promises, even across borders. With such benefits it is hard to be simply self-interested about them. 
There will be trade-offs - my good against yours - and hence the sense of justice arises (each his or her due), or fairness (equitable outcomes for each), or of greatest good for greatest number. Such standards can appeal to every actor, in whatever culture (even though the detailed content will to some extent be culturally specific), because on the whole this is the best bargain that can be struck, mindful of the required reciprocation. Often it may be hard to reach more than a truce between parties pressing their self-interested cares, enlarged as these may be into kin, nations, corporations, and other reciprocating groups. In such disputes, issues of justice and fairness will arise.

A concern to behave fairly or justly is something more than a concern for self-interest, but at least those who press such selfinterest publicly in national and international debates will have to do so in the name of fairness and justice. They will learn how to argue fairness and justice for their own sake, and perhaps will learn to feel the force of the unfairness and unjust allegations should these be used against them by others. If they cheat when they can get away with it, they themselves may realize that their conduct is unfair and unjust.

Further, there is considerable satisfaction both in being fairly and justly treated and in realizing that you keep your end of the bargain, even at some cost. What one ought to do, in any place, at any time, whoever one is, is what optimizes fairly shared values, and this is generically good, both for the self and the other, who are in parallel positions. One way of envisioning this is the so-called "original position," where one enters into contract, figuring out what is best for a person on average, oblivious to the specific circumstances of one's time and place, including one's genome and culture (Rawls, 1971).

Just this reflective element rationalizes (makes reasonable) and universalizes the recommended behavior. This is a sort of selfignorant self-interest, where one is ignorant of all the particulars of one's self, and thereby must care about what would be generally in everybody's self-interest. The altruism is "indirect" in that there is no one-to-one benefactor-to-benefitted reciprocal exchange, but the 
altruism is quite "inclusive" just because of this indirectness. One expects to be helped out in a society of reciprocating helpers.

The problem with trying to cover this with a covertly selfish Darwinian explanation is that these indirect benefits are too pervasive. They loop back to the agent himself or herself, but they loop back to everybody else, nasty or nice, with about the same probability. They do not proportionately benefit the agent because they are benefiting both community and self. Natural selection cannot "see" the benefit to select any particular person's genome, because the agent, so far as that benefit is concerned, is not differentially benefited in producing more offspring.

This is where the sense of universality, or at least panculturalism, in morality has a plausible rational basis. Values must be recognized as widely dispersed; allocated, as having extensively proliferated beyond oneself; and now the protection of values has to be shared, some in self and some in others. Ethics develops into an effort to honor the intrinsic worth of persons, beginning with self and extending to others one encounters, and comes to require protecting them and what they value simultaneously with oneself. Toward their fellows, humans struggle with impressive, if also halting, success in an effort to evolve altruism in fit proportion to egoism.

\subsection{ALTRUISM: CARING FOR OTHERS}

Caring becomes more inclusive and more complex with the emergence of an inclusive altruism. The caring agent now has a world of concern, which has to be figured into self-concern and tribal concern. This takes increasing sophistication, partially because the determinants of concern that were previously so much in evidence, and which still continue, are now often transcended with an enlarging set of concerns. Nor does it seem that the scientific accounts, which had been comfortable enough with self-interests, are satisfactory in explaining this enlarging altruism.

Although one enters into the social contract in enlightened self-interest, morality can at times rise to still more enlightened 
consideration of the interests of others. After the agent has interiorized his or her bonding to others in society, he or she may come more and more to identify with those with whom values are shared. We have already seen how this can result in an equitable distribution of benefits and lies at the root of justice. But enlightened self-interest, supporting justice, is not the upper limit of moral development. Some persons, more than others, or all persons, some of the time more than other times, will move beyond such bargaining to envision a nobler humanity still to be gained in a more disinterested altruism that takes a deeper interest in others. We can consider and intend the interest of others, as part of our enlarged network of values in which the self is constituted.

This can motivate benevolence, beyond justice, where one acts to promote values respected in others, values both already there and facilitated by one's act of benevolence. One does not just fear loss from misbehaving others, but one is drawn to protect the benefits at stake in others by behaving morally toward them. Consider the Good Samaritan, with his expansive vision of who counts as a neighbor, a role model for millennia. Parallel models can be found in other traditions, as widespread variants of the Golden Rule illustrate. Concern for raising families, earlier enlarged into patriotism, now enlarges further into the concerned helping of non-genetically related, non-tribally related others. That there are, sometimes at least, Good Samaritans on Earth is as much a fact of the matter as is natural selection. These Samaritans, too, get regenerated generation after generation.

Biologists try to set such caring behavior in a Darwinian framework, but they find this challenging (Rolston, 2004). A tribe of such Samaritans would be likely to probably do well in competition with societies from which such behavior is absent. But this is not a tribal affair; this is cross-cultural concern. The determinant concern here is an "idea" (helping a neighbor) mixed with "felt experience" (sympathetic compassion) that jumps the genetics. Such ideational concern can be transmitted nongenetically, as has indeed happened in this 
case, since the story has been widely retold and praised as a model by persons in other cultures who are neither Jews nor Samaritans. The Samaritan respects life not his own; he values life outside his own self-sector, outside his cultural sector. Neighbors are whomever one encounters that one is in a position to help.

By reductionist accounts within biology, these conscious altruistic motivations are superstructural, epiphenomenal. There are deep genetic determinants that generate the altruism, but these deep determinants must also simultaneously generate a superficial illusion of altruistic morality for the reciprocity to work sincerely enough. So the caring, although it seems to be present, is illusory. Cooperators frequently do well in society, and this works even better if the do-gooders (think they) are nobly motivated. The altruism is genuine at one level - the compassionate Samaritan believes he ought to help non-related others, and he is actively doing so - and illusory at another level. He is in fact behaving in such way as to increase the likelihood of his survival and of the survival of his children. He gains a good reputation; people think well of Good Samaritans and their children. What he really cares about is that people care about him. He is indeed helping the victim, but his larger concern is his own benefits.

Nor is this only disguised self-interest. A society of Samaritans sets up a climate of shared benefits. The Samaritan wishes to live in a world with many other Good Samaritans in it. I will help this victim; it is unlikely he will ever help me. But my helping sets up a caring climate, and some other Samaritan will help me when I fall victim. We all wish to live in such a world of "indirect reciprocity" (Alexander, 1987, p. 153; Nowak and Sigmund, 2005). With such benefits, however, it is hard to be self-interested about them in any individualistic or immediate sense. There is a feedback loop from single persons to society at large. The "unselfish" act of any particular individual benefits not only the person immediately assisted but, since it sets up a larger climate, benefits unspecified beneficiaries; and this common good promoted redounds to the benefit of the individual self. 
That entwines the "self" with the community at large, and there is nothing problematic about finding that self-interest is sometimes interlocked with the common good. We might not want to call such concerns pure altruism, but it is certainly not pure selfishness. Why not say that in certain areas, like public safety, there are shared values? Notice also that an ethical dimension is beginning to emerge, for, although those entering into such a social contract stand to gain on average, they also acquire obligations to support this contract.

To insist on interpreting all such Samaritan caring, direct and indirect, in a covert Darwinian framework may be to miss a critical new turning point in the evolution of caring: the emergence of this "idea" become "ideal" - altruistic love. What seems quite evident is that now concerns are overleaping genes. Once concerns can pass from mind to mind, people do better with genes flexible enough to track the best ideas about caring, whether their blood kin launched these concerns or not. No one doubts that ideas jump genetic lines. One does not need Semitic genes to be a Christian, any more than Plato's genes to be a Platonist, or Einstein's genes to adopt the theory of relativity. The transmission process is neural, not genetic.

We rejoice in more widely shared concerns. Biologically speaking, the concern now is that the new adherents soon cease to have any genetic relationship to the proselytizers. The commitment that one has to make transcends one's genetics. Darwinians will claim, correctly, that all such sharing behavior creates a climate in which all those involved prosper owing to the reciprocity generated. But if in this Samaritan climate all persons benefit equally, then the differential survival benefit required at the core of natural selection has vanished. Darwinian accounts are no longer plausible. Those who catch on to the Samaritan sympathies prosper, whatever their genetics.

The benefits are impossible to keep local and in-group. This moral concern is analogous to learning to build fires. Fire-building does bring survival benefit to those who learn it for the first winter, 
but by the next winter the nearby tribes, watching through the bushes, have stolen the secret. Within a decade everybody knows how, and there is no longer any differential survival benefit. The Good Samaritan ideal, like fire-building, has circumnavigated the globe, except that it is no stolen secret: it is spread by missionaries. This appearance of universalist creeds with their capacities to generate this more inclusive caring - even if more ideal than real - is one of the most remarkable forms of caring on Earth. "Do to others as you would have them do to you" helps us to cope because here is insight not just for the tribe, but for the world; indeed, if there are moral agents with values at stake in other worlds, this could be universal truth.

\subsection{ALTRUISM: CARING FOR EARTH}

Once there was no caring on Earth; today caring has gone global at least in ideal; sometimes, if but partly, in real. Ethics has been around for millennia; the Golden Rule is perennial. But we have only recently become aware of evolutionary natural history and threats to the biodiversity it has generated. Concern on Earth comes to include concern about Earth. This starts with human concerns for a quality environment, and some think this shapes all our concerns about nature from start to finish. Humans are the only self-reflective, deliberative moral agents. Ethics is for people. But humans co-inhabit Earth with five to ten million species. If the values that nature has achieved over evolutionary time are at stake, then ought not humans to find nature sometimes morally considerable in itself?

Nature has equipped Homo sapiens, the wise species, with a conscience. Perhaps conscience is less wisely used than it ought to be when, as in classical Enlightenment ethics, it excludes the global community of life from consideration, with the resulting paradox that the self-consciously moral species acts only in its collective selfinterest toward all the rest. Perhaps we humans are not so "enlightened" as once supposed - not until we reach a more considerate, environmental, Earth ethic. 
Several billion years' worth of creative toil, several million species of teeming life, have been handed over to the care of this late-coming species in which mind has flowered and morals have emerged. Ought not those of this sole moral species to do something less self-interested than count all the produce of an evolutionary ecosystem resource to be valued only for the benefits they bring? Such an attitude hardly seems biologically informed, much less ethically adequate. Its logic is too provincial for moral humanity. Such anthropocentrism is insufficiently caring.

Contemporary ethics has been concerned to be inclusive. Environmental ethics is even more inclusive. It is not simply what a society does to its slaves, women, black people, minorities, disabled, children, or future generations, but what it does to its fauna, flora, species, ecosystems, and landscapes that reveals the character of that society. Whales slaughtered, wolves extirpated, whooping cranes and their habitats disrupted, ancient forests cut, Earth threatened by global warming - these are ethical questions intrinsically, owing to values destroyed in nature, as well as also instrumentally, owing to human resources jeopardized. Humans need to include nature in their ethics; humans need to include themselves in nature.

Here is another critical threshold, recognizing a difference crucial for understanding the human possibilities in the world. Humans can not only be altruists one to another; they can be still more inclusive altruists when they recognize the claims of nonhuman others: animals, plants, species, ecosystems, a global biotic community. This most altruistic form of ethics embodies the most comprehensive caring. It really loves others. This ultimate altruism is, or ought to be, the human genius. In this sense the last becomes the first; this late-coming species with a latterday ethics is the first to see and care about the story that is taking place. This late species, just because it has the most capacity for caring, must take a leading role.

\subsection{LOGOS AND LOVE}

Einstein was impressed with the logic in the world and the human capacity to track this logic. "The eternal mystery of the world is 
its comprehensibility ... The fact that it is comprehensible is a miracle" (Einstein, 1970, p. 61). We can complement Einstein: The eternal mystery is that this world, generating rationality sufficient for worldviewing, has also generated capacities for caring necessary for appropriate respect in and of this world. Humans are "the rational animal"; that has been the classical philosophical claim. But much recent psychology and cognitive science have insisted also that humans, with their minds, are embodied, maintaining life, ever vigilant toward helps and hurts, both skin-in and skin-out. The mind is an instrument of both reasoned and unreasoned caring.

On another front, however, we might correct Einstein. "Our experience ... justifies us in believing that nature is the realisation of the simplest conceivable mathematical ideas" (Einstein, 1934, p. 36). On the contrary, nature seems bent on becoming more complex. If this is not universally true, it is at least true of Earth's natural history: The world has never yet proved as simple as we thought. In the real worlds of both nature and culture, it seems unlikely that there is any calculus of discovery, any set of formal operations that is universalizable, no general problem solver (GPS), no general or synthetic systems theory. Perhaps it is remarkable that nature has generated a human mind complex enough to discover the mathematical simplicity in theoretical physics. But the generating of such a mind has required a complex and diverse environment.

Such intelligence evolves to operate in a mixedly patterned and open world. Formal operations are only a part of such intelligence. Much complexity research has been based on computer models, with a certain paradox: that the computer models, although they may be supposed to "model" the real world, of necessity abstract from a more complex real world. They "simulate"; they are simulacra. A central puzzle here is that, although computers can "simulate" care (be programmed to maximize this or that value), they cannot in fact "care." Organisms live and die; computers do not. Organisms reproduce their species lines; computers are artifacts, not a natural kind. Organisms are naturally selected, contemporary organisms the outcome of three-and-a-half billion years of evolutionary natural 
history. Computers are not yet a century old; nor do they reproduce themselves.

Brains rapidly evolved, as we saw earlier. Such evolved intelligence, in contrast to mechanized intelligence, can and must come to care about ongoing history, and its role in it. We may desire, for instance, to preserve and enlarge family and tribe. We may come to care that democracy survives in the world, or that the wisdom of Shakespeare not be lost in the next generation, and to work to fulfill such ideals. Perhaps computers will be built that can think (play chess). But if they cannot also emote, desire, weep, love, make decisions involving free will, if they have no "affect," then they cannot do the sort of caring-thinking related to these psychological states. Intelligence includes, for example, the ability to discern analogies and parallels between outwardly dissimilar phenomena, to disambiguate equivocations. It includes the capacity to detect gestalts, to follow developing story lines. We might construct a computer with the capacity to search out mathematical simplicity, but what would it be like to construct a computer with a good sense of plot, caring about how the story ends? The embodied mind is not hardware, not software; it is (so to speak) wetware that must be kept wet, sometimes with tears.

We must attach logic to loving, if we are to understand what natural history has done. Reason is yoked with emotion, cognition with caring. So far from resisting this, let us welcome it. But as we welcome this connection, we have also to recognize that science, whatever else it discovers for us about the evolution of caring, is incompetent henceforth to direct it. When we yoke logic and love, we reach yet another critical threshold: the gap between the is and the ought. For that one needs ethics. Ethics is the choice of the right, in the face of temptation to do otherwise. "Temptation" is poorly embodied in computers, almost as poorly as right and wrong is addressed in science. The natural forces, thrusting up the myriad species, produced one that, so to speak, reached escape velocity, transcending the merely natural with cares super to anything previously natural. A complement of this eternal mystery is the possibility for 
better and worse caring, for noble and for misplaced caring, for good and evil. Humans are capable of pride, avarice, flattery, adulation, courage, charity, forgiveness, prayer.

R. L. Stevenson pondered the "incredible properties" of dust stirring to give rise to this creature struggling for responsible caring:

What a monstrous spectre is this man, the disease of the agglutinated dust, lifting alternate feet or lying drugged with slumber; killing, feeding, growing, bringing forth small copies of himself; grown upon with hair like grass, fitted with eyes that move and glitter in his face; a thing to set children screaming; - and yet looked at nearlier, known as his fellows know him, how surprising are his attributes! Poor soul, here for so little, cast among so many hardships, filled with desires so incommensurate and so inconsistent, savagely surrounded, savagely descended, irremediably condemned to prey upon his fellow lives: who should have blamed him had he been of a piece with his destiny and a being merely barbarous? And we look and behold him instead filled with imperfect virtues: infinitely childish, often admirably valiant, often touchingly kind; sitting down, amidst his momentary life, to debate of right and wrong and the attributes of the deity; rising up to do battle for an egg or die for an idea; singling out his friends and his mate with cordial affection; bringing forth in pain, rearing with longsuffering solicitude, his young. To touch the heart of his mystery, we find in him one thought, strange to the point of lunacy: the thought of duty; the thought of something owing to himself, to his neighbour, to his God: an ideal of decency, to which he would rise if it were possible; a limit of shame, below which, if it be possible, he will not stoop.

(Stevenson, 1903, pp. 291-295)

The embodied story is the human legacy of waking up to good and evil (as in Genesis 1-2), or the dreams of hope for the future (as 
with visions of the kingdom of God). This, as much as logic and love, may be the differentia of the human genius. The generation of such caring is as revealing as anything else we know about natural history. The fact of the matter is that evolution has generated ideals in caring.

Nor should we be surprised that this generating has been a long struggle. The evolutionary picture is of nature laboring in travail. The root idea in the English word "nature," going back to Latin and Greek origins, is that of "giving birth." Birthing is creative genesis, which certainly characterizes evolutionary nature. Birthing (as every mother knows) involves struggle. Earth slays her children, a seeming evil, but bears an annual crop in their stead. The "birthing" is nature's orderly self-assembling of new creatures amidst this perpetual perishing. Life is ever "conserved," as biologists might say; life is perpetually "redeemed," as theologians might say. From our perspective, let us call it the "generation and regeneration of caring."

Perhaps the planetary set-up is an accident, but the ongoing processes after the set-up seem to be loaded with fertility. Life depends on a statistical stability blended with open contingency; in the short term all lose, death is inevitable; but then again, in the long term life persists, phoenix-like, in the midst of its destruction. There is a kind of "promise" in nature, not only in the sense of potential that is promising, but also in the sense of reliability in the Earthen set-up that is right for life. Perhaps nature does not care, but nature is a caregenerator, since nature does evolve, over the millennia, billions of species in almost every nook and cranny of Earth in which caring for life does take place.

Complex systems, we have been saying, have to be understood at multiple levels. So move to a different perspective on this Earthen story. This churn of materials, perpetually agitated and irradiated with energy, is not only to be seen as indifferent resource but as prolific source. The negentropy is as objectively there as the entropy, the achievements as real as the drifting cycles and random walks. Against the indifference, we now must counter that the systemic 
results have been prolific, today five million species flourishing in myriads of diverse ecosystems. One species is challenged to care for the whole community of life, challenged today more than ever before in human history. To say that there is nothing but systemic indifference seems to ignore these principal results of natural history, including those embodied in us. Even those who retain doubts about natural systems cannot doubt that in human systems caring is omnipresent. Nor that better caring is urgent and among our most challenging tasks.

Dealing with causes, we interpret the results in terms of the precedents (A causes B). Dealing with stories, and histories, however, we may need to interpret the beginnings by thinking back from the endings ( $\mathrm{Y}$ has been unfolding toward $\mathrm{Z}$ ). Complexity is often to be understood not just bottom up, but top down. To that we add, in closing, that the caring-complexity in which we find ourselves must be understood comprehensively - in terms of conclusions, not just origins. That ending lies ahead, but en route, we humans are at the forefront of the story. Increased caring, like the increased complexity that supports it, is an ever open niche. That invites us to see such a world, and our task in it, as sacred, even divine.

\section{REFERENCES}

Alexander, R. D. (1987). The Biology of Moral Systems. New York: Aldine de Gruyter.

Bak, P. (1996). How Nature Works: The Science of Self-Organized Criticality. New York: Springer-Verlag.

Bonner, J. T. (1998). The origins of multicellularity. Integrative Biology, 1: 27-36.

Christiansen, M. H., and Kirby, S. (2003). Language evolution: The hardest problem in science? In Language Evolution, eds M. H. Christiansen and S. Kirby. New York: Oxford University Press, 1-15.

Dawkins, R. (1989). The Selfish Gene, new ed. New York: Oxford University Press.

Deacon, T. W. (1997). The Symbolic Species: The Co-Evolution of Language and the Brain. New York: Norton.

Draganski, B., et al. (2004). Neuroplasticity: changes in grey matter induced by training. Nature, 427: 311-312.

Dunbar, R. I. M., and Shultz, S. (2007). Evolution in the social brain. Science, 317: 1344-1347. 


\section{HOLMES ROLSTON, III}

Einstein, A. (1934). On the method of theoretical physics. In The World as I Set It. New York: Covici-Friede Publishers, 30-40.

Einstein, A. (1970). Out of My Later Years. Westport, CT: Greenwood Press.

Elbert, T., et al. (1995). Increased cortical representation of the fingers of the left hand in string players. Science, 270: 305-307.

Herring, C. D., et al. (2006). Comparative genome sequencing of Escherichia coli allows observation of bacterial evolution on a laboratory timescale. Nature Genetics, 38: 1406-1412.

Hume, D. (1972). Dialogues Concerning Natural Religion, ed. H. D. Aiken. New York: Hafner Publishing.

Kauffman, S. A. (1991). Antichaos and adaptation. Scientific American, 265 (no. 2): 78-84.

Kauffman, S. A. (1993). The Origins of Order: Self- Organization and Selection in Evolution. New York: Oxford University Press.

Langford, D. J., et al. (2006). Social modulation of pain as evidence for empathy in mice. Science, 312: 1967-1970.

Mackenzie, D. (2006). The Poincaré conjecture proved. Science, 314: 1848-1849.

Maguire, E. A., et al. (2000). Navigation-related structural change in the hippocampi of taxi drivers. Proceedings of the National Academy of Sciences of the United States of America, 97(8): 4398-4403.

Maturana, H. R., and Varela, F. J. (1980). Autopoiesis and Cognition: The Realization of the Living. Dordrecht, Boston: D. Reidel Publishing.

Maynard Smith, J. (2000). The concept of information in biology. Philosophy of Science, 67: 177-194.

Mayr, E. (1988). Toward a New Philosophy of Biology. Cambridge, MA: Harvard University Press.

Mechelli, A., et al. (2004). Neurolinguistics: structural plasticity in the bilingual brain. Nature, 431:757

Merzenich, M. A. (2001). The power of mutable maps. In Neuroscience: Exploring the Brain, 2nd ed., eds M. F. Bear, B. W. Connors, and M. A. Paradiso. Baltimore: Lippincott Williams and Wilkins, 418-452.

Nowak, M. A., and Sigmund, K. (2005). Evolution of indirect reciprocity. Nature, 437: 1291-1298.

Oliveri, P., and Davidson, E. H. (2007). Built to run, not fail. Science, 315: 1510-1511.

Pennisi, E. (2006). Brain evolution on the far side. Science, 314: 244-245.

Prigogine, I., and Stengers, I. (1984). Order out of Chaos: Man's New Dialogue with Nature. New York: Bantam Books.

Rawls, J. (1971). A Theory of Justice. Cambridge, MA: Harvard University Press.

Rolston, H. (2004). The Good Samaritan and his genes. In Evolution and Ethics: Human Morality in Biological and Religious Perspective, eds P. Clayton and J. Schloss. Grand Rapids, MI: William B. Eerdmans Publishing, 238-252. 
Russell, R. J., et al., eds. (1999). The Neurosciences and the Person: Scientific Perspectives on Divine Action. Berkeley, CA: Center for Theology and the Natural Sciences.

Sober, E., and Wilson, D. S. (1998). Unto Others: The Evolution and Psychology of Unselfish Behavior. Cambridge, MA: Harvard University Press.

Solé, R. V., and Bascompte, J. (2006). Self-Organization in Complex Ecosystems. Princeton: Princeton University Press.

Stevenson, R. L. (1903). Pulvis et umbra. In Across the Plains. New York: Charles Scribner's Sons, 289-301.

Venter, J. C, et al. (2001). The sequence of the human genome. Science, 291:1304-1351.

Williams, G. C. (1988). Huxley's evolution and ethics in sociobiological perspective. Zygon, 23: 383-407.

Wilson, E. O. (1978). On Human Nature. Cambridge, MA: Harvard University Press.

Wilson, E. O. (1984). Biophilia. Cambridge, MA: Harvard University Press. 